\title{
ВНЕШНЕТОРГОВАЯ ПОЛИТИКА КНР НА СОВРЕМЕННОМ ЭТАПЕ РАЗВИТИЯ ГЛОБАЛЬНОЙ ЭКОНОМИКИ
}

\author{
(c) 2019 Чжан Ифэй \\ аспирант кафедры «Экономическая теория и менеджмент» \\ Московский педагогический государственный университет, Россия, Москва \\ E-mail: zd100606@yandex.ru
}

В данной статье анализируются особенности внешнеторговой политики КНР в современных условиях глобализации мирохозяйственных связей. Определяется место и роль Китая в структуре мировой экономики. Осуществляется оценка торгово-экономического потенциала КНР.

Ключевые слова: экономика КНР, экспорт, импорт, внешнеторговая политика, глобализация мирохозяйственных связей, глобализация мировой экономики

Введение. На современном этапе развития мировой экономики в условиях ускоряющихся процессов глобализации Китайская Народная Республика является одним из ведущих игроков в сфере мирового производства и мировой торговли соответственно. Вследствие чего динамика и структура развития экономики Китая во многом предопределяет будущую внешнеторговую политику не только тихоокеанской Азии, но и всей мировой экономик в целом [1, 4].

Столь существенное влияние на мировую экономику стало возможным благодаря следующим факторам:

- ускоренной индустриализации экономики Китая в 50-60-е годы прошлого века;

- существенным притоком иностранного капитала в страну начиная с 70-х годов прошлого века;

- высоким объемом трудовых ресурсов и их относительной дешевизной;

- существенными залежами ресурсов.

Данные факторы позволили Китаю за короткий срок сформировать мощную и стабильную экономику, которая на сегодняшний день продуцируем почти 14\% мирового ВВП.

Изложение основного материала. Внешнеторговая политика Китайской Народной Республики на сегодняшний день ориентирована на увеличение производственных процессов и наращивание экспорта готовой продукции (доля ресурсной составляющей в системе экспорта крайне мала). Это обуславливается присутствием большого количества сырьевых ресурсов в Юго-Восточной Азии с одной стороны, высоким притоком иностранных инвестиций в экономику Китая с другой стороны и относительно дешевыми трудовыми ресурсами с третьей [5].

В рамках более, предметного раскрытия тем данного научного исследования осуществим анализ динамики валового внутреннего продукта Китайской Народной Республики за период с 2010 года по 2017 год соответственно.

Для чего воспользуемся нижеприведенной диаграммой (рис. 1) на которой наглядно отображено изменение динамики данного показателя за исследуемый период времени.

Как можно увидеть из вышеприведенной диаграммы за отчетный период произошли следующие изменения в динамике объемов валового внутреннего продукта Китая:

- ВВП за исследуемый период вырос на 100\% или 6,13 триллионов долларов США, с 6,1 трлн. долларов в 2010 году до 12,23 трлн. долларов по итогам 2017 года соответственно;

- за исследуемый период несколько сократились темпы ежегодного прироста объемов ВВП, если в 2010 году темп роста валового внутреннего продукта составлял 10,6\%, то к 2017 году он снизился до показателя в 6,9\% годовых;

- за исследуемый период увеличил свою долю в мировом объеме ВВП на 3,8 п.п. с 10\% в 2010 году до 13,8\% по итогам 2017 года соответственно;

- подобный рост был вызван близостью сырьевого кластера, стабильным благоприятным инвестиционным климатом и относительно недорогой базой трудовых ресурсов.

Продолжая анализировать внешнеторговую политику Китайской Народной Республики, на современном этапе развития глобальной экономики осуществим оценку объемов экспортно-импортных операций государства за период с 2010 по 2017 год соответственно.

Для чего воспользуемся нижеприведенной диаграммой (рис. 2), на которой наглядно отображено изменение динамики объемов экспорта и импорта товаров и услуг КНР за анализиру- 


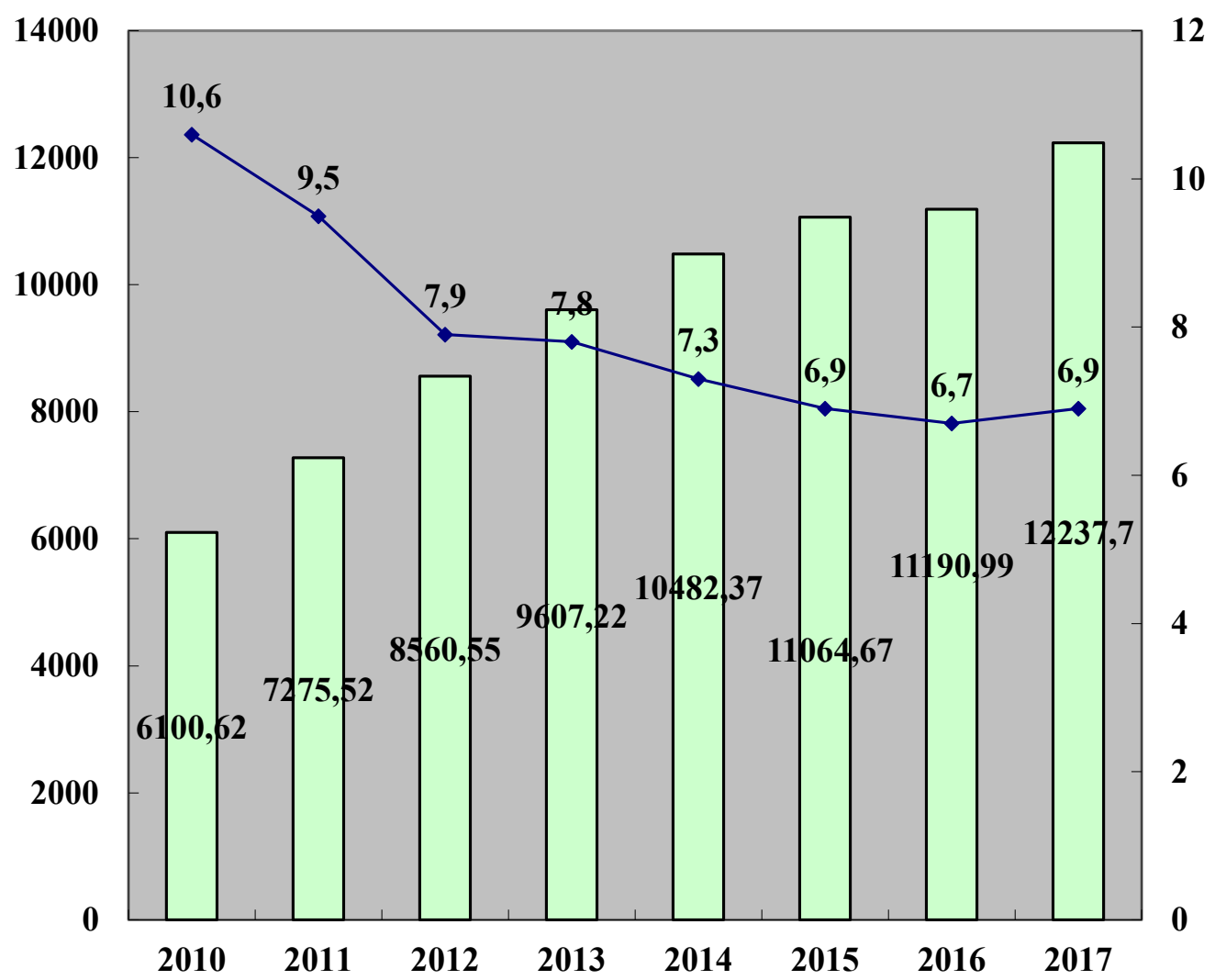

Puc. 1. ВВП Китая в 2010-2017 году

(в млрд. долларов - левая шкала и динамика роста в\% - правая шкала) [7-8]

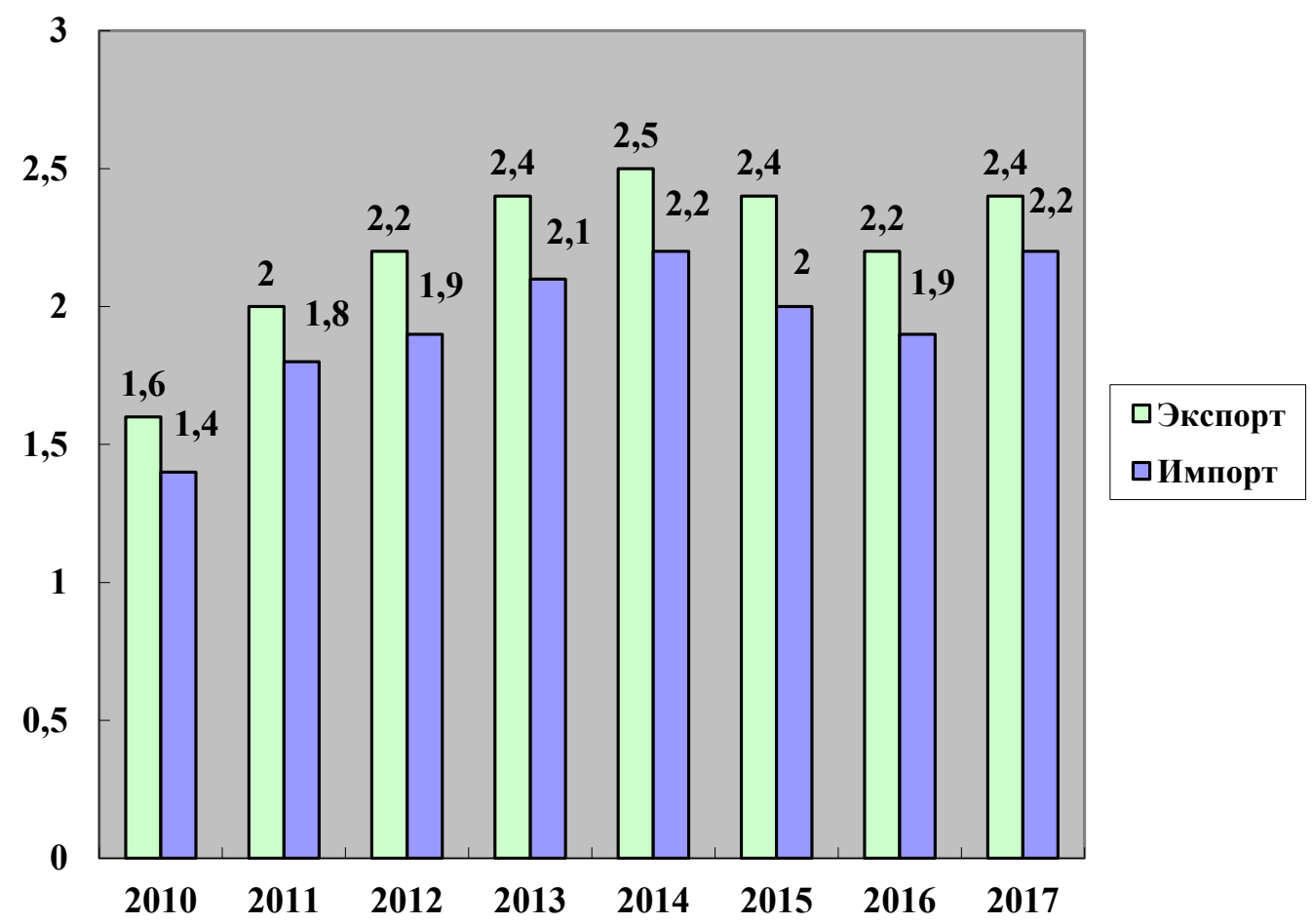

Puc. 2. Динамика экспорта и импорта товаров и услуг КНР в 2010-2017 году (в трлн. долларов) [2-3] 
емый временной период.

Как можно увидеть из вышеприведенной диаграммы за отчетный период произошли следующие изменения в системе внешнеторговой деятельности КНР:

- за анализируемый временной период объемы экспорта Китайской Народной Республики в системе внешнеторговых операций страны выросли на 50\% или 800 млрд. долларов соответственно, с 1600 млрд. долларов США в 2010 году до показателя в 2400 млрд. долларов по итогам 2017 года соответственно;

- за анализируемый временной период объемы импорта Китайской Народной Республики в системе внешнеторговых операций страны выросли на 57\% или 800 млрд. долларов соответственно, с 1400 млрд. долларов США в 2010 году до показателя в 2200 млрд. долларов по итогам 2017 года соответственно;

- весь анализируемый период объем экспорта товаров и услуг КНР превышал объем импорта товаров и услуг Китая. В целом можно отметить, что профицит внешнеторговой деятельности Китайской Народной Республики за исследуемый период находился в диапазоне
200-300 млрд. долларов;

- доля экспорта Китая в мировом экспорте выросла на 0,49 п.п. с 9,26\% в 2010 году до 9,75 по итогам 20117 года соответственно, что свидетельствует о постепенном увеличении влияния Китая на мировой рынок товаров и услуг.

В рамках более, предметного раскрытия темы данного исследования в целом и экспортно-импортной политики Китайской Народной Республики в частности, осуществим анализ структурной динамики экспорта Китая за период с 2010 по 2017 год соответственно.

Для чего воспользуемся нижеприведенной диаграммой (рис. 3) на которой наглядно отображено изменение динамики ключевых структурных элементов экспорта КНР.

Как можно увидеть из вышеприведенной диаграммы за анализируемый период произошли следующие изменения в структуре экспорта Китайской Народной Республики:

- доля машин и оборудования в структуре экспортной деятельности КНР выросла на 1,1 п.п., с 47,4\% в 2010 году до 48,5\% по итогам 2017 года соответственно;

- доля продукции текстильной промышлен-

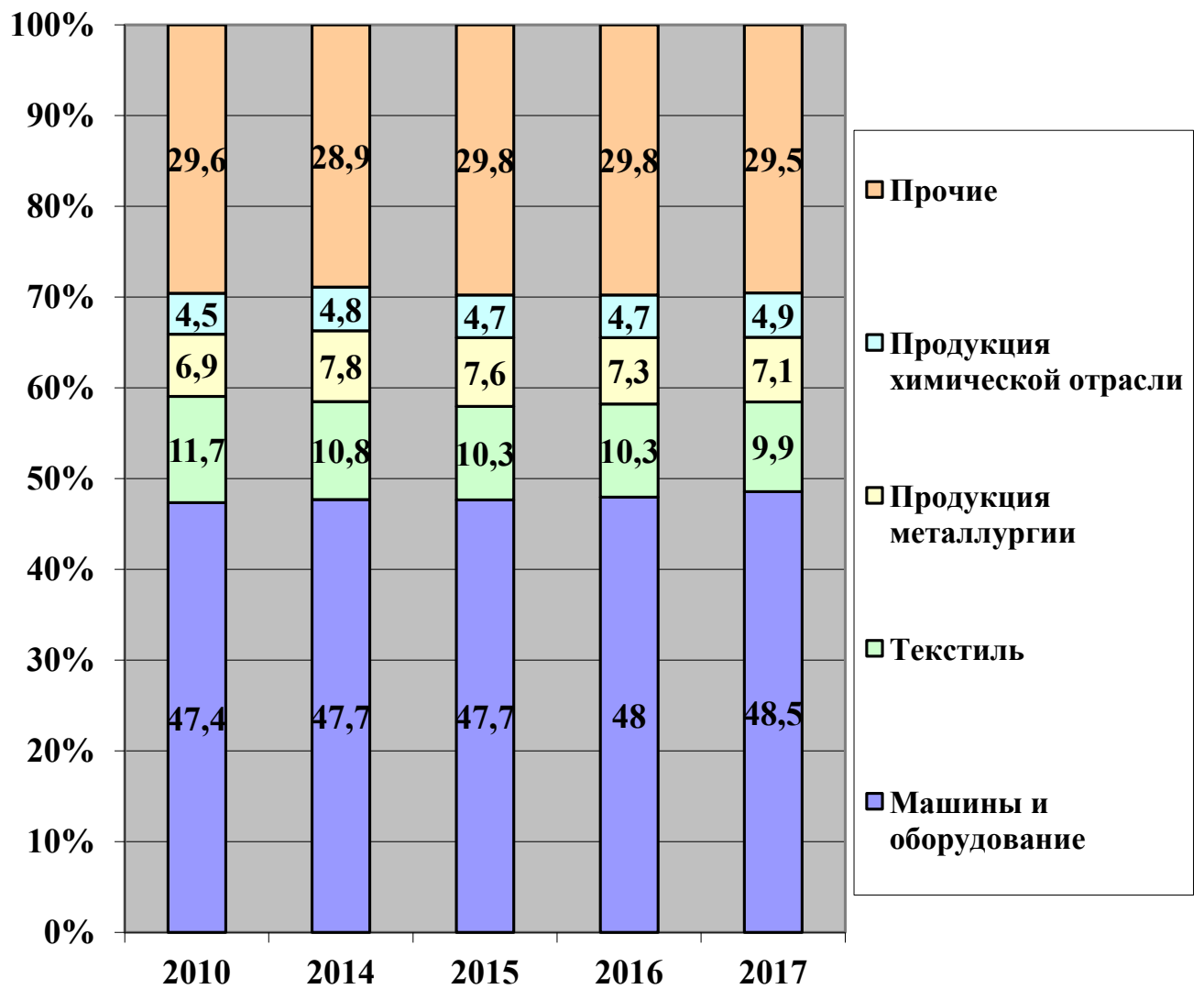

Pис. 3. Структура экспорта товаров КНР в 2010-2017 годах [6] 
ности Китая снизилась на 1,78 п.п. с 11,7\% в 2010 году до 9,9\% по итогам 2017 года соответственно;

- доля продукции металлургической отрасли в структуре экспортной деятельности КНР выросла на 0,2 п.п., с 6,9\% в 2010 году до 7,1\% по итогам 2017 года соответственно;

- доля продукции химической промышленности Китайской Народной Республики выросла на 0,4 п.п. с 4,5\% в 2010 году до 4,9\% по итогам 2017 года соответственно;

- доля прочих структурных элементов в системе экспорта КНР за анализируемый период снизилась на 0,1 п.п., с 29,6\% в 2010 году до 29,5\% по итогам 2017 года.

Аналогично в рамках более, предметного раскрытия темы данного исследования в целом и экспортно-импортной политики Китайской Народной Республики в частности, осуществим анализ структурной динамики импорта Китая за период с 2010 по 2017 год соответственно.

Для чего воспользуемся нижеприведенной диаграммой (рис. 4) на которой наглядно отображено изменение динамики ключевых структурных элементов импорта Китая.

Как можно увидеть из вышеприведенной диаграммы за анализируемый период произошли следующие изменения в структуре импорта Ки- тайской Народной Республики:

- доля машин и оборудования выросла с 30,5\% в 2010 году до 42,6 по итогам 2017 года;

- доля минеральных продуктов выросла с 23,2\% в 2010 году до 30,3 по итогам 2017 года;

- доля продукции металлургии снизилась с 9\% в 2010 году до 7,9\% по итогам 2017 года;

- продукция химической отрасли выросла с 7,7\% в 2010 году до 10,4\% по итогам 2017 года;

- доля продукции сельского хозяйства выросла с 3,4\% в 2010 году до 5,3 по итогам 2017 года соответственно.

Заключение. Как итог данного исследования можно сделать следующие выводы:

- внешнеторговая политика Китайской Народной Республики ориентирована на высокие темпы прироста ВВП и увеличение объемов экспорта в мировой торговле, что позволяет стране продуцировать 14\% мирового ВВП и $10 \%$ мирового экспорта;

- во внешней торговле экспорт существенно превосходит импорт на 200-300 млрд. долларов в среднем;

- в экспортных потоках КНР преобладает продукция с высоким уровнем добавленной стоимости (технологическая продукция, продукция отраслей переработки);

- импортирует Китай преимущественно ре-

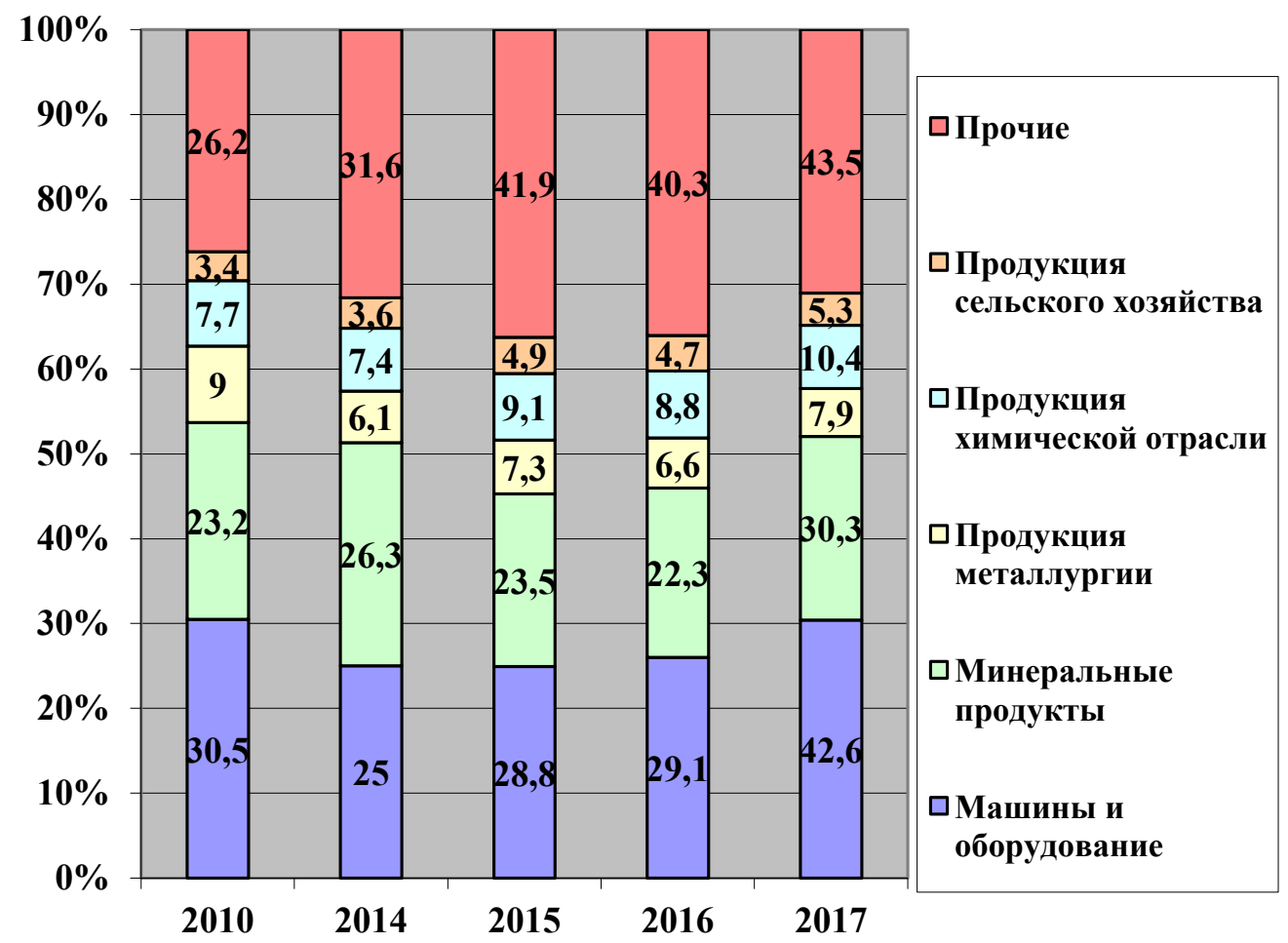

Puc. 4. Структура импорта товаров КНР в 2010-2017 годах [6] 
сурсную базу (минеральные продукты, продукцию сельскохозяйственной отрасли);

- внешнеторговая политика КНР обладает высокой степенью эффективности, что позволяет государству быть в мировых лидерах в системе глобальной экономики.

\section{Библиографический список}

1. Алиджанова О.Т. Китайский фактор в развитии мировой экономики / О.Т. Алиджанова [Электронный ресурс] - Режим доступа: https://cyberleninka.ru/article/n/kitayskiy-faktor-v-razvitii-mirovoy-ekonomiki (Дата обращения: 15.03.2019)

2. Китай - экспорт товаров и услуг [Электронный ресурс] - Режим доступа: https://knoema.ru/atlas/\%D0\%9A\% D0\%B8\%D1\%82\%D0\%B0\%D0\%B9/\%D0\%AD\%D0\%BA\%D1\%81\%D0\%BF\%D0\%BE\%D1\%80\%D1\%82-\%D1\%82\%D 0\%BE\%D0\%B2\%D0\%B0\%D1\%80\%D0\%BE\%D0\%B2-\%D0\%B8-\%D1\%83\%D1\%81\%D0\%BB\%D1\%83\%D0\%B3 (Дата обращения: 15.03.2019)

3. Китай - импорт товаров и услуг [Электронный ресурс] - Режим доступа: https://knoema.ru/atlas/\%D0\%9A\% D0\%B8\%D1\%82\%D0\%B0\%D0\%B9/\%D0\%98\%D0\%BC\%D0\%BF\%D0\%BE\%D1\%80\%D1\%82-\%D1\%82\%D0\%BE\%D0 \%B2\%D0\%B0\%D1\%80\%D0\%BE\%D0\%B2-\%D0\%B8-\%D1\%83\%D1\%81\%D0\%BB\%D1\%83\%D0\%B3 (Дата обращения: 15.03.2019)

4. Никулина О.В. Направления развития внешнеторговой политики Китая на основе укрепления международного сотрудничества с американскими и российскими компаниями в высокотехнологичных отраслях экономики [Электронный ресурс] - Режим доступа: https://cyberleninka.ru/article/n/napravleniya-razvitiya-vneshnetorgovoy-politiki-kitaya-na-osnove-ukrepleniya-mezhdunarodnogo-sotrudnichestva-s-amerikanskimi-i (Дата обращения: 15.03.2019)

5. Ю Хань Развитие современной внешней политики КНР / Ю Хань [Электронный ресурс] - Режим доступа: https://cyberleninka.ru/article/n/razvitie-sovremennoy-vneshney-politiki-knr (Дата обращения: 15.03.2019)

6. China (OEC) [Электронный ресурс] - Режим доступа: https://atlas.media.mit.edu/ru/profile/country/chn/ (Дата обращения: 15.03.2019)

7. China GDP [Электронный ресурс] - Режим доступа: https://tradingeconomics.com/china/gdp (Дата обращения: 15.03.2019)

8. GDP growth (annual\%) [Электронный ресурс] - Режим доступа: https://data.worldbank.org/indicator/NY.GDP. MKTP.KD.ZG?end=2017\&locations=MY-CN\&start=2010 (Дата обращения: 15.03.2019) 